\title{
Correction to: Acute and Chronic Toxicity Pattern in Ketamine Abusers in Hong Kong
}

\section{Yiu-Cheung Chan ${ }^{1}$}

Published online: 8 June 2021

(C) American College of Medical Toxicology 2021

Correction to: J. Med. Toxicol. (2012) 8:267-270 https://doi.org/10.1007/s13181-012-0229-z

Please note that author given name and surname were inadvertently transposed in this article as original published.

Chan Yiu-Cheung should have read Yiu-Cheung Chan.

The original article has been corrected.

Publisher's Note Springer Nature remains neutral with regard to jurisdictional claims in published maps and institutional affiliations.

The online version of the original article can be found at https://doi.org/ 10.1007/s13181-012-0229-z

$\triangle$ Yiu-Cheung Chan

chanyc3@ha.org.hk

1 Hong Kong Poison Information Centre, K3A,

United Christian Hospital,

130 Hip Wo Street, Kwun Tong,

Hong Kong, SAR, People's Republic of China 